\title{
No association between Helicobacter pylori infection and diabetes mellitus among a general Japanese population: a cross-sectional study
}

\author{
Takashi Tamura ${ }^{1,2^{*}}$, Emi Morita1,3, Sayo Kawai ', Tae Sasakabe', Yuka Sugimoto ${ }^{1}$, Nana Fukuda', Shino Suma 1,4, \\ Hiroko Nakagawa ${ }^{1,5}$, Rieko Okada' ${ }^{1}$ Asahi Hishida ${ }^{1}$, Mariko Naito ${ }^{1}$, Nobuyuki Hamajima ${ }^{6}$ and Kenji Wakai ${ }^{1}$
}

\begin{abstract}
Several case-control studies have reported that patients with diabetes mellitus (DM) had a higher prevalence of Helicobacter pylori infection than those without DM, but these findings remain equivocal. Additionally, there are few studies examining associations between East Asian CagA-positive H. pylori and DM. This cross-sectional study aimed to investigate whether $\mathrm{H}$. pylori infection was a possible risk factor for DM in a general Japanese population. The study included 5165 subjects (1467 men, 3698 women) aged 35-69 years from the Daiko Study, part of the Japan MultiInstitutional Collaborative Cohort Study. A urinary anti-H. pylori antibody was used to detect H. pylori infection. The medical history of physician-diagnosed DM was confirmed by self-administered questionnaire. The odds ratios (ORs) and their $95 \%$ confidence intervals (Cls) for DM (current and former) were calculated using unconditional logistic regression analysis, adjusting for age, sex, educational status, alcohol use, smoking status, body mass index, energy intake, and physical activity. The prevalence of DM was $4.6 \%$ (95 \% Cl 3.7-5.6\%) among 1878 participants with $H$. pylori infection and $3.2 \%$ (2.6-3.8\%) among 3287 without the infection $(p=0.009)$. The crude, age-adjusted, and multivariate-adjusted ORs for DM in those with the infection relative to those without were 1.47 (95\% Cl 1.10-1.97), $1.02(0.76-1.38)$, and $0.97(0.71-1.32)$, respectively. We found a significantly higher DM prevalence among those with H. pylori infection than among those without. However, almost all the difference in prevalence could be explained by the older age of those infected. Our findings did not support an association between H. pylori infection and DM.
\end{abstract}

Keywords: Helicobacter pylori, East Asian CagA, Diabetes mellitus, Cross-sectional study, Japan

\section{Background}

Helicobacter pylori infection is a major risk factor for gastric cancer (Montecucco and Rappuoli 2001) and is also well known as a causative factor for ulcers, atrophic gastritis, mucosa-associated lymphoid tissue lymphoma, and intestinal metaplasia (Labenz and Borsch 1994; Asaka et al. 2001; Wundisch et al. 2005). Helicobacter pylori infection has been estimated to be present in half of the world's population, and it has been reported to be higher

\footnotetext{
*Correspondence: ttamura@gifu-u.ac.jp

2 Department of Epidemiology and Preventive Medicine, Gifu University

Graduate School of Medicine, 1-1 Yanagido, Gifu 501-1194, Japan

Full list of author information is available at the end of the article
}

in developing countries than in industrialized countries (Suerbaum and Michetti 2002; Correa and Piazuelo 2008).

Some studies reported that H. pylori is a possible risk factor for cardiovascular disease and metabolic syndrome, potentially mediated by elevations in inflammatory molecules, such as C-reactive protein and interleukin-6 (Georges et al. 2003; Nabipour et al. 2006). Helicobacter pylori infection has been linked with the activation of toll-like receptors, resulting in energy harvesting and fat accumulation, which lead to insulin resistance (Manco et al. 2010). Several cross-sectional studies showed that $H$. pylori infection was associated with diabetes mellitus

\section{Springer}


(DM) (Chen and Blaser 2012; Hsieh et al. 2013; Han et al. 2015). A recent prospective cohort study also reported that $H$. pylori infection was correlated with a significantly high hazard ratio for DM (Jeon et al. 2012). However, the association between $H$. pylori infection and the risk of DM remains controversial, because several cross-sectional studies reported that $H$. pylori was not associated with insulin resistance or the prevalence of DM (Ko et al. 2001; Anastasios et al. 2002; Howard et al. 2008; Lutsey et al. 2009), and there are few studies reporting such associations among large populations in East Asia, where the more pathogenic East Asian CagA-positive strain of $H$. pylori is dominant (Fock and Ang 2010).

We previously reported the prevalence of $H$. pylori infection in 2008-2010 among a large general Japanese population (Tamura et al. 2012). In the present study, we aimed to investigate whether or not $H$. pylori infection was associated with DM in a cross-sectional study in the same population.

\section{Methods}

Subjects, lifestyle, and medical history of diabetes mellitus The study included 5165 participants (1467 men, 3698 women) aged 35-69 years in the Daiko Study, part of the Japan Multi-Institutional Collaborative Cohort Study (J-MICC Study) (The J-MICC Study Groups 2007; Morita et al. 2011). The participants were enrolled at the Daiko Medical Center from June 2008 to May 2010.

All participants provided written informed consent and completed a questionnaire on their lifestyle, including education, alcohol use, smoking status, exercise, dietary habits, history of $H$. pylori eradication treatment, and medical history of physician-diagnosed DM (current, former, or never). Of 5172 initial participants, we excluded four who withdrew from the study, two with no answer about their DM medical history, and one without a urine sample for the detection of anti-H. pylori antibody. The J-MICC Study and the Daiko Study were both approved by the Ethics Review Committee of Nagoya University School of Medicine (approved numbers were 253 and 618 , respectively).

\section{Detection of $H$. pylori infection}

An antibody kit for urine, Rapiran (Otsuka Pharmaceutical Co., Ltd., Tokyo, Japan) was used to detect H. pylori infection. The sensitivity and specificity of the assay were 89.6 and $93.8 \%$, respectively, based on biopsies of gastric mucosa as a gold standard (Yamamoto et al. 2000; Graham and Reddy 2001; Fujisawa et al. 2001).

\section{Estimation of physical activity levels}

The daily metabolic equivalent (MET)-hours/day (MET levels $\times$ hours/day) were estimated based on our questionnaire. Subjects were asked about the average hours per day (none, $<1,1$ to $<3,3$ to $<5,5$ to $<7,7$ to $<9,9$ to $<11$, and $\geq 11 \mathrm{~h}$ ) of four types of physical activity: heavy physical work, walking, standing, and sitting. The following time scores were assigned: 0 for none, 0.5 for $<1,2$ for 1 to $<3,4$ for 3 to $<5,6$ for 5 to $<7,8$ for 7 to $<9,10$ for 9 to $<11$, and 11 for $\geq 11 \mathrm{~h}$. On the basis of previous studies (Inoue et al. 2008a, b), the following MET scores were assigned: 4.5 for heavy physical work, 3.0 for walking, 2.0 for standing, and 1.5 for sitting. We defined and included only $\geq 3.0$ METs activity as physical activity, and each MET-hours/day (i.e., heavy physical work and walking) was calculated by multiplying the MET intensity for each activity by the daily time score for each activity.

Leisure-time physical activity was calculated using the international physical activity questionnaire (IPAQ) as in a previous study (Higashibata et al. 2012). IPAQ was developed and validated as an instrument for crossnational monitoring of physical activity and inactivity (Craig et al. 2003). Total MET-hours/day (total physical activity) were then estimated by adding the sum of daily physical activity to that of leisure time for those who responded to all the questions $(n=5101)$.

\section{Estimation of total energy intake}

Energy intake (kcal/day) was estimated using a short food frequency questionnaire for each subject. The questionnaire has been validated for estimation of energy and nutrient intakes in Japanese subjects by referring to dietary records (Tokudome et al. 2004, 2005; Goto et al. 2006; Imaeda et al. 2007).

\section{Statistical analysis}

Differences in mean values between those with and without $H$. pylori infection were examined by the Student $t$ test, and the differences in proportions were tested using the Chi square test. Confidence intervals (CIs) of $H$. pylori infection or DM prevalence were estimated based on a binominal distribution.

We calculated a prevalence rate ratio of DM for the infection. Additionally, the following odds ratios (ORs) of DM (current or former) for $H$. pylori infection (positive) with their $95 \%$ CIs were estimated using unconditional logistic regression models: crude OR, age-adjusted OR, age- and sex-adjusted OR, and multivariate-adjusted OR, adjusted for age (as a continuous variable), sex, education ( $\leq 12,13-15$, or $\geq 16$ years), alcohol use (current, former, or never), smoking status (current, former, or never), body mass index (BMI, as a continuous variable), energy intake (as a continuous variable), and total physical activity (as a continuous variable) as confounders. Those who drank at least once a month were defined as current 
drinkers. Those with any covariate missing were excluded from the multivariate analysis $(n=85)$.

The statistical power to detect given ORs for DM with an $\alpha$ error of 0.05 was calculated based on the sample size, the infection rate of $H$. pylori, and the DM prevalence after study completion. A $p$-value of $<0.05$ was considered statistically significant. All the statistical analyses were performed using STATA/IC 12.1 (STATA Corp., College Station, TX, USA).

\section{Results}

Table 1 compares the characteristics of 5165 study subjects between those with $H$. pylori infection and those without. In total, $28.4 \%$ were men and $71.6 \%$ were women. Mean age \pm standard deviation was $53.6 \pm 10.3$ years in men and $52.2 \pm 10.3$ years in women, with $58.5 \%$ of participants aged $\geq 50$ years. A total of 190 participants reported a history of DM (current or former) in the questionnaire. Participants without $H$. pylori infection tended to have a higher education. The proportions of current drinkers were $55.0 \%$ for those without infection and $52.6 \%$ for those with infection, while respective proportions of current smokers were 11.3 and $12.7 \%$; these differences were not statistically significant. Means of age and BMI were significantly higher in those with $H$. pylori infection than those without $(p<0.001$ and $p=0.002$, respectively). Mean total physical activity was marginally higher in those with the infection than in those without $(p=0.09)$. Average energy intake was not significantly different between those with and without infection.

Figure 1 shows the DM prevalence according to infection status and age. The prevalence was $4.6 \%$ (95\% CI 3.7-5.6\%) among those with $H$. pylori infection and $3.2 \%$ (95 \% CI 2.6-3.8 \%) among those without, resulting in a significant difference $(p=0.009)$. The difference within each age group, however, did not reach statistical significance.

Table 2 summarizes the ORs for DM in relation to $H$. pylori infection. The prevalence rate ratio and the crude OR of DM for those with the infection relative to those without were greater than unity: 1.45 (95 \% CI 1.09-1.91) and 1.47 (95\% CI 1.10-1.97), respectively. The age-adjusted OR, however, showed no association: 1.02 (95\% CI 0.76-1.38). The age- and sex-adjusted and the multivariate-adjusted ORs also indicated no association: 0.98 (95\% CI 0.72-1.32) and 0.97 (95\% CI 0.711.32), respectively. Including $167 \mathrm{H}$. pylori-negative subjects who had a history of eradication treatment as positive subjects had little effect on the ORs (date not shown).

\section{Discussion}

In this study, we examined the association of $H$. pylori infection with medical history of DM. Overall, DM prevalence was significantly higher in those with $H$. pylori infection than those without infection. However, after adjusting for age as a confounder, $H$. pylori infection was not associated with DM in a general Japanese population.

Helicobacter pylori is transmitted from person to person through oral-oral or fecal-oral routes during early childhood (from 1 to 3 years old), and the infection usually persists unless eradication therapy has been successful (Goodman and Correa 1995). Infection among adults is possible, but highly limited (Brown 2000). Thus, H. pylori-positive subjects in this study would have been infected for decades (Tamura et al. 2012). Several case-control studies have reported that $H$. pylori infection was significantly associated with DM (Bener et al. 2007; Devrajani et al. 2010). Additionally, a prospective cohort study and a meta-analysis of observational studies also showed that $H$. pylori infection is a risk factor for DM (Jeon et al. 2012; Zhou et al. 2013). Some biological mechanisms may explain the association. First, altered glucose metabolism may produce chemical changes in the gastric mucosa that help to detect $H$. pylori infection (de Luis et al. 1998). Second, H. pylori gastric infection increases secretion of proinflammatory cytokines, resulting in changes in the structure of insulin receptor interfering with the interaction between its receptor and insulin (Bener et al. 2007). Our study also found a significantly higher prevalence rate ratio and crude OR of DM in relation to $H$. pylori infection. However, the age-adjusted OR was almost unity, which means that the significant difference in prevalence of DM between those with and without the infection could be explained by the older age of those infected and the higher prevalence of DM in the elderly. This explanation was further supported by the fact that DM prevalence was not significantly different between infection statuses in each age stratum (Fig. 1). Since the risk of DM is influenced by lifestyle factors such as alcohol use, smoking status, dietary habits, and exercise, we estimated the multivariateadjusted ORs of DM according to infection status, and again found no association. Our results indicate that $H$. pylori infection may not be a risk factor for DM in Japanese subjects. This is in accordance with other studies that found negative or neutral results for such an association (Demir et al. 2008; Ciortescu et al. 2009).

A previous meta-analysis for the association between $H$. pylori infection and DM reported a significantly high OR (1.33, 95 \% CI 1.08-1.64) (Zhou et al. 2013), although the analysis mainly included case-control studies and only 
Table 1 Background characteristics of the study subjects according to $H$. pylori infection

\begin{tabular}{|c|c|c|c|c|}
\hline \multirow[t]{2}{*}{ Characteristic } & \multirow[t]{2}{*}{ Total $(n=5165)$} & \multicolumn{3}{|l|}{ H. pylori } \\
\hline & & Uninfected $(n=3287)$ & Infected $(n=1878)$ & $p$ \\
\hline \multicolumn{5}{|l|}{ Age (years) } \\
\hline Mean \pm SD & $52.5 \pm 10.3$ & $50.7 \pm 10.3$ & $55.8 \pm 9.6$ & \multirow[t]{2}{*}{$<0.001$} \\
\hline Range & $35-69$ & $35-69$ & $35-69$ & \\
\hline \multicolumn{5}{|l|}{ Sex, n (\%) } \\
\hline Men & $1467(28.4)$ & $891(27.1)$ & $576(30.7)$ & \multirow[t]{2}{*}{0.006} \\
\hline Women & $3698(71.6)$ & $2396(72.9)$ & $1302(69.3)$ & \\
\hline \multicolumn{5}{|c|}{ Diabetes mellitus, n (\%) } \\
\hline Current & $156(3.0)$ & $84(2.6)$ & $72(3.8)$ & \multirow[t]{3}{*}{0.07} \\
\hline Former & $34(0.7)$ & $20(0.6)$ & $14(0.8)$ & \\
\hline None & $4975(96.3)$ & $3183(96.8)$ & $1792(95.4)$ & \\
\hline \multicolumn{5}{|l|}{ Education, n (\%) } \\
\hline$\leq 12$ years & $2088(40.4)$ & $1213(36.9)$ & $875(46.6)$ & \multirow[t]{4}{*}{$<0.001$} \\
\hline$\geq 13-15$ years & $1535(29.7)$ & $1025(31.2)$ & $510(27.2)$ & \\
\hline$\geq 16$ years & $1524(29.5)$ & $1037(31.5)$ & $487(25.9)$ & \\
\hline Unknown & $18(0.4)$ & $12(0.4)$ & $6(0.3)$ & \\
\hline \multicolumn{5}{|l|}{ Alcohol use, n (\%) } \\
\hline Current & $2798(54.2)$ & $1809(55.0)$ & $989(52.6)$ & \multirow[t]{4}{*}{0.24} \\
\hline Former & $105(2.0)$ & $61(1.9)$ & $44(2.4)$ & \\
\hline Never & $2261(43.8)$ & $1416(43.1)$ & $845(45.0)$ & \\
\hline Unknown & $1(0.02)$ & $1(0.03)$ & $0(0.0)$ & \\
\hline \multicolumn{5}{|c|}{ Smoking status, n (\%) } \\
\hline Current & $609(11.8)$ & $371(11.3)$ & $238(12.7)$ & \multirow[t]{4}{*}{0.10} \\
\hline Former & $1025(19.8)$ & $636(19.3)$ & $389(20.7)$ & \\
\hline Never & $3530(68.3)$ & $2280(69.4)$ & $1250(66.6)$ & \\
\hline Unknown & $1(0.02)$ & $0(0.0)$ & $1(0.05)$ & \\
\hline \multicolumn{5}{|l|}{ BMI $\left(\mathrm{kg} / \mathrm{m}^{2}\right)^{\mathrm{a}}$} \\
\hline Mean \pm SD & $21.7 \pm 3.2$ & $21.6 \pm 3.2$ & $21.9 \pm 3.2$ & \multirow[t]{2}{*}{0.002} \\
\hline Range & $11.5-52.8$ & $13.6-42.4$ & $11.5-52.8$ & \\
\hline \multicolumn{5}{|c|}{ Energy intake (kcal/day) } \\
\hline Mean \pm SD & $1612 \pm 326$ & $1611 \pm 324$ & $1614 \pm 329$ & 0.35 \\
\hline \multicolumn{5}{|c|}{ Physical activity (MET-hours/day) } \\
\hline Mean \pm SD & $14.5 \pm 9.0$ & $14.3 \pm 8.9$ & $14.8 \pm 9.1$ & 0.09 \\
\hline
\end{tabular}

$B M I$ body mass index, SD standard deviation, $M E T$ metabolic equivalent

a Data were missing for one subject with no information on body weight

a few studies in East Asian populations. Our findings in a large Japanese population should contribute to understanding the association in East Asian individuals. The East Asian CagA-positive strain of $H$. pylori is a well-known risk factor for gastric cancer (Azuma et al. 2004). Interestingly, there are two major subtypes of CagA, the East Asian and the Western types, and the former subtype is dominant in Japan except for Okinawa Prefecture (Azuma 2004) on the southernmost islands of the country. Only one-half to two-thirds of Western infections carry Western CagA, while nearly all East Asian strains have East Asian CagA (Van Doorn et al. 1999). Some previous studies reporting the association between $H$. pylori and DM suggested that Western CagA increased the risk of DM (Jeon et al. 2012; Zhou et al. 2013). In contrast, our study may indicate that the East Asian CagA strain is not associated with DM. Infection with the East Asian CagA-positive strain is clearly involved in the pathogenesis of gastric cancer, with persistent inflammation induced by CagA. However, the increased inflammation may not necessarily enhance insulin resistance and fat accumulation as has been suggested in previous studies in Asian populations (Howard et al. 2008; Lutsey et al. 2009). The mechanism by which only Western strains induced DM remains to be elucidated. 


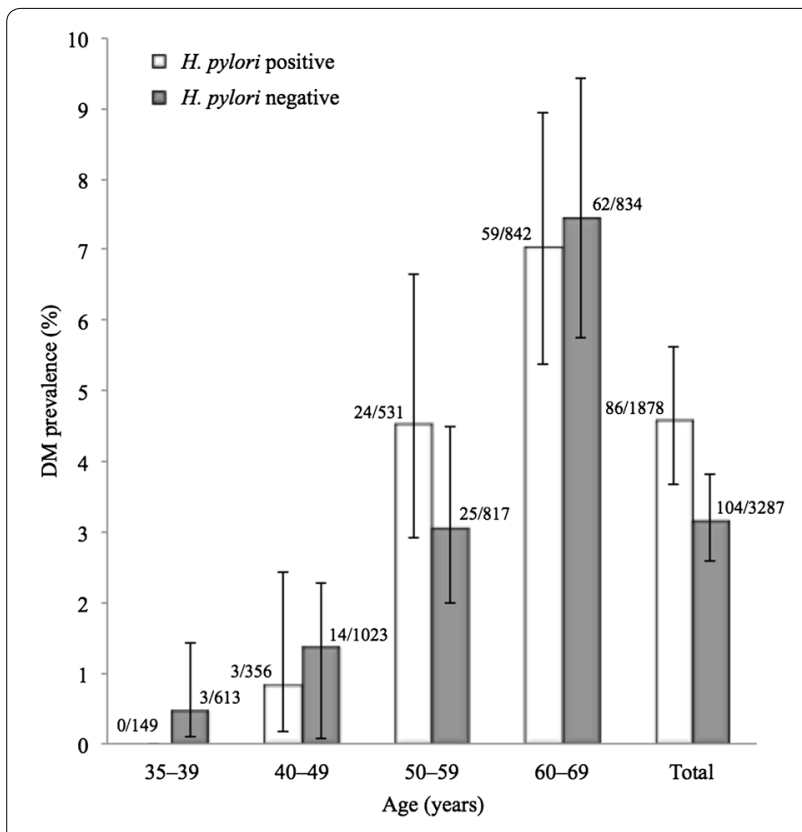

Fig. 1 Prevalence of diabetes mellitus among those with H. pylori infection and those without. DM diabetes mellitus. Numbers at tops of bars show $\mathrm{n}$ of DM $(+) / \mathrm{n}$. Error bars indicate $95 \%$ confidence intervals

Table 2 Prevalence rate ratio and odds ratios and $95 \%$ confidence intervals for diabetes mellitus in relation to $\boldsymbol{H}$. pylori infection

\begin{tabular}{lll}
\hline & \multicolumn{1}{l}{ H. pylori } \\
\cline { 2 - 3 } & Uninfected $(\mathbf{n}=\mathbf{3 2 8 7})$ & Infected $(\mathbf{n}=\mathbf{1 8 7 8})$ \\
\hline Diabetes mellitus & & $1792(95.4)$ \\
Never, $\mathrm{n}(\%)$ & $3183(96.8)$ & $86(4.6)$ \\
Current or former, $\mathrm{n}(\%)$ & $104(3.2)$ & $1.45(1.09-1.91)$ \\
Prevalence rate ratio & 1 & $1.47(1.10-1.97)$ \\
Crude OR & 1 & $1.02(0.76-1.38)$ \\
Age-adjusted OR & 1 & $0.98(0.72-1.32)$ \\
Age- and sex-adjusted & 1 & \\
OR & & $0.97(0.71-1.32)$ \\
Multivariate-adjusted & 1 & \\
OR &
\end{tabular}

OR odds ratio

a Adjusted for age, sex, education, alcohol use, smoking status, BMI, energy intake, and total physical activity

Our study involved a large population that lends support to our conclusion. There are limitations in this study. First, fasting blood glucose level and glycosylated hemoglobin $\left(\mathrm{HbA}_{1 \mathrm{c}}\right)$ values were not directly measured. However, the sensitivity and specificity of our questionnaire for DM were 74.4 and $98.1 \%$, respectively, when based on a $\mathrm{HbA}_{1 \mathrm{c}}$ (National Glycohemoglobin Standardization
Program) value $\geq 6.5 \%$, which was the gold standard for diagnosis of DM among 5009 subjects in the Shizuoka area, in another part of the J-MICC study (Asai et al. 2009). Therefore, we believe that case ascertainment using self-report was reasonably valid for the present study. Second, we could not differentiate the type of DM (type 1 or 2) due to the limitation of data, but the prevalence of type $1 \mathrm{DM}$ in Japan is much lower than that of type 2 DM (International Diabetes Federation 2013). Third, we did not use the well-validated serological tests for Helicobacter pylori infection. However, according to previous studies, the sensitivity and specificity of urinary test used in our study are similar to those of the validated serological tests (Yamamoto et al. 2000; Burucoa et al. 2013). We employed the urinary test because it could be superior to serum tests in terms of the convenience and non-invasiveness to participants. Finally, this study had statistical power of $69.2,74.6$, and $83.6 \%$ to detect ORs of $1.45,1.50$, and 1.55 , respectively, for the infected versus uninfected. The power was $43.7 \%$, if the true OR was 1.33 based on a previous meta-analysis (Zhou et al. 2013). This study had a relatively high $\beta$ error possibility (i.e., $56.3 \%$ ) to overlook such an association, which means that a slight increase in the risk for DM in relation to $H$. pylori cannot be ruled out.

\section{Conclusion}

Our findings suggest that infection of East Asia CagApositive H. pylori is not a risk factor for DM. Further prospective cohort studies of non-DM subjects with or without $H$. pylori infection are warranted.

\section{Abbreviations \\ BMl: body mass index; $\mathrm{Cl}$ : confidence interval; $\mathrm{DM}$ : diabetes mellitus; $\mathrm{HbA}_{1 \mathrm{c}}$ : glycosylated hemoglobin; H. pylori: Helicobacter pylori; IPAQ: international physical activity questionnaire; J-MICC: Japan-Multi Institutional Collaborative Cohort; MET: metabolic equivalent; OR: odds ratio; SD: standard deviation.}

\section{Authors' contributions}

TT and NH conceived of the study, and participated in its design. EM, SK, MN and KW managed the study. TT analyzed the data. TS, YS, NF, SS, HN, RO, and $\mathrm{AH}$ contributed to recruit participants and collect data in the study. TT and KW prepared the draft. All authors read and approved the final manuscript.

\section{Author details}

${ }^{1}$ Department of Preventive Medicine, Nagoya University Graduate School of Medicine, 65 Tsurumai-cho, Showa-ku, Nagoya 466-8550, Japan. ${ }^{2}$ Department of Epidemiology and Preventive Medicine, Gifu University Graduate School of Medicine, 1-1 Yanagido, Gifu 501-1194, Japan. ${ }^{3}$ Environmental Planning Laboratory, Department of Forest Management, Forestry and Forest Products Research Institute, National Research and Development Agency, 1 Matsunosato, Tsukuba 305-8687, Japan. ${ }^{4}$ Department of Oral Disease Research, National Center for Geriatrics and Gerontology, 7-430 Morioka-cho, Obu 474-8511, Japan. ${ }^{5}$ Division of Epidemiology and Prevention, Aichi Cancer Center Research Institute, 1-1 Kanokoden, Chikusa-ku, Nagoya 464-8681, Japan. ${ }^{6}$ Department of Healthcare Administration, Nagoya University Graduate School of Medicine, 65 Tsurumai-cho, Showa-ku, Nagoya 466-8550, Japan. 


\section{Acknowledgements}

This work was supported in part by Grants-in-Aid for Scientific Research on Priority Areas (No. 17015018) and Innovative Areas (No. 22150001) from the Ministry of Education, Culture, Sports, Science and Technology of Japan.

\section{Competing interests}

The authors declare that they have no competing interests.

Received: 10 June 2015 Accepted: 24 September 2015

Published online: 13 October 2015

\section{References}

Anastasios R, Goritsas C, Papamihail C, Trigidou R, Garzonis P, Ferti A (2002) Helicobacter pylori infection in diabetic patients: prevalence and endoscopic findings. Eur J Intern Med 13:376

Asai Y, Naito M, Suzuki M, Tomoda A, Kuwabara M, Fukada Y, Okamoto A, Oishi S, Ikeda K, Nakamura T, Misu Y, Katase S, Tokumasu S, Nishio K, Ishida Y, Hishida A, Morita E, Kawai S, Okada R, Wakai K, Tamakoshi A, Hamajima N (2009) Baseline data of Shizuoka area in the Japan Multi-Institutional Collaborative Cohort Study (J-MICC Study). Nagoya J Med Sci 71:137-144

Asaka M, Sugiyama T, Nobuta A, Kato M, Takeda H, Graham DY (2001) Atrophic gastritis and intestinal metaplasia in Japan: results of a large multicenter study. Helicobacter 6:294-299

Azuma T (2004) Helicobacter pylori CagA protein variation associated with gastric cancer in Asia. J Gastroenterol 39:97-103

Azuma T, Yamazaki S, Yamakawa A, Ohtani M, Muramatsu A, Suto H, Ito Y, Dojo M, Yamazaki Y, Kuriyama M, Keida Y, Higashi H, Hatakeyama M (2004) Association between diversity in the Src homology 2 domain-containing tyrosine phosphatase binding site of Helicobacter pylori CagA protein and gastric atrophy and cancer. J Infect Dis 189:820-827

Bener A, Micallef R, Afifi M, Derbala M, Al-Mulla HM, Usmani MA (2007) Association between type 2 diabetes mellitus and Helicobacter pylori infection. Turk J Gastroenterol 18:225-229

Brown LM (2000) Helicobacter pylori: epidemiology and routes of transmission. Epidemiol Rev 22:283-297

Burucoa C, Delchier JC, Courillon-Mallet A, de Korwin JD, Mégraud F, Zerbib F, Raymond J, Fauchère JL (2013) Comparative evaluation of 29 commercial Helicobacter pylori serological kits. Helicobacter 18:169-179

Chen Y, Blaser MJ (2012) Association between gastric Helicobacter pylori colonization and glycated hemoglobin levels. J Infect Dis 205:1195-1202

Ciortescu I, Sfarti C, Stan M, Graur M, Stanciu C (2009) Prevalence of Helicobacter pylori infection in patients with diabetes mellitus. Rev Med Chir Soc Med Nat lasi 113:1048-1055

Correa P, Piazuelo MB (2008) Natural history of Helicobacter pylori infection. Dig Liver Dis 40:490-496

Craig CL, Marshall AL, Sjöström M, Bauman AE, Booth ML, Ainsworth BE, Pratt M, Ekelund U, Yngve A, Sallis JF, Oja P (2003) International physical activity questionnaire: 12-country reliability and validity. Med Sci Sports Exerc 35:1381-1395

de Luis DA, de la Calle H, Roy G, de Argila CM, Valdezate S, Canton R, Boixeda D (1998) Helicobacter pylori infection and insulin-dependent diabetes mellitus. Diabetes Res Clin Pract 39:143-146

Demir M, Gokturk HS, Ozturk NA, Kulaksizoglu M, Serin E, Yilmaz U (2008) Helicobacter pylori prevalence in diabetes mellitus patients with dyspeptic symptoms and its relationship to glycemic control and late complications. Dig Dis Sci 53:2646-2649

Devrajani BR, Shah SZ, Soomro AA, Devrajani T (2010) Type 2 diabetes mellitus: a risk factor for Helicobacter pylori infection: a hospital based case-control study. Int J Diabetes Dev Countries 30:22-26

Fock KM, Ang TL (2010) Epidemiology of Helicobacter pylori infection and gastric cancer in Asia. Gastroenterol Hepatol 25:479-486

Fujisawa T, Kaneko T, Kumagai T, Akamatsu T, Katsuyama T, Kiyosawa K, Tachikawa T, Kosaka O, Machikawa F (2001) Evaluation of urinary rapid test for Helicobacter pylori in general practice. J Cin Lab Anal 15:154-159

Georges JL, Rupprecht HJ, Blankenberg S, Poirier O, Bickel C, Hafner G, Nicaud $V$, Meyer J, Cambien F, Tiret L, AtheroGene Group (2003) Impact of pathogen burden in patients with coronary artery disease in relation to systemic inflammation and variation in genes encoding cytokines. Am J Cardiol 92:515-521

Goodman KJ, Correa P (1995) The transmission of Helicobacter pylori: a critical review of the evidence. Int J Epidemiol 24:875-887

Goto C, Tokudome Y, Imaeda N, Takekuma K, Kuriki K, Igarashi F, Ikeda M, Tokudome S (2006) Validation study of fatty acid consumption assessed with a short food frequency questionnaire against plasma concentration in middle-aged Japanese people. Scand J Nutr 50:77-82

Graham DY, Reddy S (2001) Rapid detection of anti-Helicobacter pylori lgG in urine using immunochromatography. Aliment Pharmacol Ther 15:699-702

Han X, Li Y, Wang J, Liu B, Hu H, Li X, Yang K, Yuan J, Yao P, Wei S, Wang Y, Liang Y, Miao X, Zhang X, Guo H, Yang H, Wu T, He M (2015) Helicobacter pylori infection is associated with type 2 diabetes among a middle- and old-age Chinese population. Diabetes Metab Res Rev. doi:10.1002/ dmrr.2677

Higashibata T, Hamajima N, Naito M, Kawai S, Yin G, Suzuki S, Kita Y, Niimura H, Imaizumi T, Ohnaka K, Arisawa K, Shigeta M, Ito H, Mikami H, Kubo M, Tanaka H, Wakai K (2012) eNOS genotype modifies the effect of leisuretime physical activity on serum triglyceride levels in a Japanese population. Lipids Health Dis 11:150

Howard BV, Best L, Comuzzie A, Ebbesson SO, Epstein SE, Fabsitz RR, Howard WJ, Silverman A, Wang H, Zhu J, Umans J (2008) C-reactive protein, insulin resistance, and metabolic syndrome in a population with a high burden of subclinical infection: insights from the Genetics of Coronary Artery Disease in Alaska Natives (GOCADAN) study. Diabetes Care 31:2312-2314

Hsieh MC, Wang SS, Hsieh YT, Kuo FC, Soon MS, Wu DC (2013) Helicobacter pylori infection associated with high $\mathrm{HbA} 1 \mathrm{c}$ and type 2 diabetes. Eur J Clin Invest 43:949-956

Imaeda N, Goto C, Tokudome Y, Hirose K, Tajima K, Tokudome S (2007) Reproducibility of a short food frequency questionnaire for Japanese general population. J Epidemiol 17:100-107

Inoue $\mathrm{M}$, Iso H, Yamamoto S, Kurahashi N, Iwasaki M, Sasazuki S, Tsugane S, Japan Public Health Center-Based Prospective Study Group (2008a) Daily total physical activity level and premature death in men and women: results from a large-scale population-based cohort study in Japan (JPHC study). Ann Epidemiol 18:522-530

Inoue M, Yamamoto S, Kurahashi N, Iwasaki M, Sasazuki S, Tsugane S, Japan Public Health Center-based Prospective Study Group (2008b) Daily total physical activity level and total cancer risk in men and women: results from a large-scale population-based cohort study in Japan. Am J Epidemiol 168:391-403

International Diabetes Federation (2013) IDF diabetes atlas, 6th edn. International Diabetes Federation, Brussels

Jeon CY, Haan MN, Cheng C, Clayton ER, Mayeda ER, Miller JW, Aiello AE (2012) Helicobacter pylori infection is associated with an increased rate of diabetes. Diabetes Care 35:520-525

Ko GT, Chan FK, Chan WB, Sung JJ, Tsoi CL, To KF, Lai CW, Cockram CS (2001) Helicobacter pylori infection in Chinese subjects with type 2 diabetes. Endocr Res 27:171-177

Labenz J, Borsch G (1994) Evidence for essential role of Helicobacter pylori in gastric ulcer disease. Gut 35:19-22

Lutsey PL, Pankow JS, Bertoni AG, Szklo M, Folsom AR (2009) Serological evidence of infections and type 2 diabetes: the MultiEthnic Study of Atherosclerosis. Diabet Med 26:149-152

Manco M, Putignani L, Bottazzo GF (2010) Gut microbiota, lipopolysaccharides, and innate immunity in the pathogenesis of obesity and cardiovascular risk. Endocr Rev 31:817-844

Montecucco C, Rappuoli R (2001) Living dangerously: how Helicobacter pylori survives in the human stomach. Nat Rev Mol Cell Biol 2:457-466

Morita E, Hamajima N, Hishida A, Aoyama K, Okada R, Kawai S, Tomita K, Kuriki S, Tamura T, Naito M, Kondo T, Ueyama J, Kimata A, Yamamoto K, Hori Y, Hoshino J, Hamamoto R, Tsukamoto S, Onishi J, Hagikura S, Naito H, Hibi S, Ito Y, Wakai K (2011) Study profile on baseline survey of Daiko Study in the Japan Multi-Institutional Collaborative Cohort Study (J-MICC Study). Nagoya J Med Sci 73:187-195

Nabipour I, Vahdat K, Jafari SM, Pazoki R, Sanjdideh Z (2006) The association of metabolic syndrome and Chlamydia pneumoniae, Helicobacter pylori, cytomegalovirus, and herpes simplex virus type 1: the Persian Gulf Healthy Heart Study. Cardiovasc Diabetol 5:25 
Suerbaum S, Michetti P (2002) Helicobacter pylori infection. N Engl J Med 347:1175-1186

Tamura T, Morita E, Kondo T, Ueyama J, Tanaka T, Kida Y, Hori Y, Inoue S, Tomita K, Okada R, Kawai S, Hishida A, Naito M, Wakai K, Hamajima N (2012) Prevalence of Helicobacter pylori infection measured with urinary antibody in an urban area of Japan, 2008-2010. Nagoya J Med Sci 74:63-70

The J-MICC Study Groups (2007) The Japan Multi-Institutional Collaborative Cohort Study (J-MICC Study) to detect gene-environment interactions for cancer. Asian Pac J Cancer Prev 8:317-323

Tokudome S, Goto C, Imaeda N, Tokudome Y, Ikeda M, Maki S (2004) Development of a data-based short food frequency questionnaire for assessing nutrient intake by middle-aged Japanese. Asian Pac J Cancer Prev $5: 40-43$

Tokudome Y, Goto C, Imaeda N, Hasegawa T, Kato R, Hirose K, Tajima K, Tokudome S (2005) Relative validity of a short food frequency questionnaire for assessing nutrient intake versus three-day weighed diet records in middle-aged Japanese. J Epidemiol 15:135-145

Van Doorn LJ, Figueiredo C, Mégraud F, Pena S, Midolo P, Queiroz DM, Carneiro F, Vanderborght B, Pegado MD, Sanna R, De Boer W, Schneeberger PM, Correa P, Ng EK, Atherton J, Blaser MJ, Quint WG (1999) Geographic distribution of vacA allelic types of Helicobacter pylori. Gastroenterology 116:823-830

Wundisch T, Thiede C, Morgner A, Dempfle A, Günther A, Liu H, Ye H, Du MQ, Kim TD, Bayerdörffer E, Stolte M, Neubauer A (2005) Long-term follow up of gastric MALT lymphoma after Helicobacter pylori eradication. J Clin Oncol 23:8018-8024

Yamamoto S, Uemura N, Okamoto S, Yamaguchi S, Mashiba H, Tachikawa T (2000) A new rapid test for detecting anti-Helicobacter pylori antibody excreted into urine. Helicobacter 5:160-164

Zhou X, Zhang C, Wu J, Zhang G (2013) Association between Helicobacter pylori infection and diabetes mellitus: a meta-analysis of observational studies. Diabetes Res Clin Pract 99:200-208

\section{Submit your manuscript to a SpringerOpen ${ }^{\odot}$ journal and benefit from:}

- Convenient online submission

- Rigorous peer review

- Immediate publication on acceptance

- Open access: articles freely available online

- High visibility within the field

- Retaining the copyright to your article

Submit your next manuscript at $\boldsymbol{~ s p r i n g e r o p e n . c o m ~}$ 